\title{
SARS-COV-2 Infection and Specific Antibody Detection on Health Care Workers from a Military Hospital in Madrid, Spain
}

\author{
María Simón Sacristán ${ }^{1}$. Carmen Ybarra de Villavicencio ${ }^{1}$ Ana Collazos Blanco ${ }^{1}$ - María Elga Mayo Montero ${ }^{2}$. \\ María del Carmen Ariñez Fernández ${ }^{2} \cdot$ Adolfo Suárez Prieto $^{2} \cdot$ María Isabel Zamora Cintas $^{1} \cdot$ María Mateo Maestre $^{1}$
}

Received: 9 November 2020 / Accepted: 12 May 2021 / Published online: 22 June 2021

(c) The Author(s), under exclusive licence to Springer Science+Business Media, LLC, part of Springer Nature 2021

\begin{abstract}
This study aims to assess the COVID-19 seroprevalence in HCW at the Hospital Central de la Defensa Gómez Ulla (HCDGU) (Madrid). From 27 April to 10 June 2020 nasopharyngeal swab and serum samples from employees were processed in order to evaluate their seroprevalence and infective situation. Employees were classified according to their exposure to SARSCoV-2 infection as high, moderate, and low exposure groups (level 1, level 2, and level 3, respectively). A specific real-time polymerase chain reaction (RT-PCR) was run to diagnose each patient, whereas the qualitative detection of IgG antibodies to SARS-CoV-2 was performed by means of an immunoassay. In total, $2781 \mathrm{HCW}$ were screened. From this sample, 30 employees (1.1\%) were infected with SARS-CoV-2 and 450 (16.2\%) were positive to SARS-CoV-2-IgG antibodies. The seroprevalence was higher in the high exposure group. The seroprevalence of antibodies against SARS-CoV-2 among employees without any COVID-19 training was higher than in those who received COVID-19 training (14.5\% vs $18.6 \%, P=0.035)$. The seroprevalence in military and civilian personnel in level 1 was $18.2 \%$ and $20.0 \%$, respectively $(P=0.4616)$, while in level 2 it was $6.0 \%$ and $16.0 \%(P=0.0008)$ and in level 3 it was $16.7 \%$ and $10.2 \%(P=0.0315)$. The results from the present study have shown that the high exposure group and HCW not receiving specific training against COVID-19 showed higher seroprevalence. Furthermore, the military employees from this hospital presented low percentage of seroprevalence.
\end{abstract}

\section{Introduction}

María Simón Sacristán

marysaymon@hotmail.com

María Mateo Maestre

mmatmae@oc.mde

Carmen Ybarra de Villavicencio

cybarrav@gmail.com

Ana Collazos Blanco

acollazosblanco@gmail.com

María Elga Mayo Montero

mmaymon1@oc.mde.es

María del Carmen Ariñez Fernández

marifer@oc.mde.es

Adolfo Suárez Prieto

abie@oc.mde.es

María Isabel Zamora Cintas

maribel.zamora.cintas@gmail.com

1 Servicio de Microbiología y Parasitología, Hospital Central de la Defensa Gómez Ulla, Madrid, Spain

2 Instituto de Medicina Preventiva de la Defensa, Madrid, Spain
On December 2019, a new virus called SARS-CoV-2 emerged in the city of Wuhan, China [1]. This virus has since spread to many other countries and throughout the world [2] and on 11 March 2020 was declared a pandemic by the World Health Organization. It represents a great challenge for health care systems; so far 123,216,178 cases have been reported and 2,714,517 persons have died worldwide. Spain, with 3,234,319 cases and 73,744 deaths by 23 March 2021 , is considered one of the most affected countries in the European Union [3]. In order to avoid the disease spreading, hospitals in Spain have implemented capacities by canceling elective admissions.

The most frequent clinical symptoms of COVID-19 are fever, sore throat, cough, and shortness of breath [4]. The main route of transmission is person-to-person spread. Health care workers represent a vulnerable cohort for infection due to frequent and close contact with COVID-19 patients [5]. The principal microbiological diagnostic test to prove the presence of virus is the Polymerase Chain Reaction (PCR), a molecular technique that detects the RNA of 
the virus. On the other hand, other methods based on the detection of virus antigens have been evaluated, showing lower sensitivity as compared to PCR [6, 7]. Therefore, PCR remains the gold standard for the detection of for SARSCoV-2 [8]. Different studies have been published exploring the combination of PCR and serological techniques, trying to increase the sensitivity of the microbiological diagnosis $[9,10]$. The rationale to do antibody testing is to identify individuals who have developed immunity after infection, which could protect against subsequent reinfection. Moreover, by evaluating seroprevalence of antibodies, we could monitor the extent of virus spread and the population's herd immunity at a societal level [11].

Seroprevalence studies can determine the prevalence of the population who has suffered from recent or past infection $[12,13]$. These studies are accurate to evaluate the whole community, but also for smaller groups, such as exposed and vulnerable persons in nursing homes and health care facilities.

In this sense medical records on health care workers would help to better organize the health care resource planning according to their prevalence to COVID-19 during this pandemic crisis [12]. Although there is substantial evidence proving the immunological responses against SARS-CoV-2, the dynamics of this process remains unclear. As an example, today we still do not know the time needed for seroconversion, the antibody levels acquired, or the correlation between antibody levels and protection against reinfection $[14,15]$. Moreover, the duration of a protective immunity also remains uncertain [16].

The aim of this study was to assess the seroprevalence of COVID-19 in health care workers of the Hospital Central de la Defensa Gómez Ulla (Madrid).

\section{Materials and Methods}

This study was carried out at Hospital Central De la Defensa Gomez Ulla, a Spanish military tertiary hospital located in Madrid where most of the patients attended are civilians. Thanks to a cooperation agreement between the Ministry of Defense and the Autonomous Community of Madrid, this is fully integrated in the Public Health System and represents a reference hospital center that provides a 400-bed capacity for a population of approximately 125,000 inhabitants in southern Madrid. The workforce of the hospital is composed of both military and civilian staff. Study participants were recruited from the entire hospital employees. This study period ranged from April 27 to June 10, 2020.

\section{Study Design}

The present investigation was designed as a cross-sectional study. Samples from the hospital employees were taken by the Occupational Health and Safety Service to evaluate the seroprevalence and infective situation. Nasopharyngeal swab and serum samples were obtained from 2781 health care workers and processed at the Microbiology Laboratory for diagnostic purposes.

Employees were classified into three levels according to their exposure to SARS-CoV-2 infection:

- Level 1 (High exposure group; $n=1250$ ): workers who were in direct contact with infected patients (or suspected of being infected with SARS-CoV-2), such as nursing services and medical teams.

- Level 2 (Moderate exposure group; $n=969$ ): workers who were not in direct contact with SARS-CoV-2 patients but they had daily contact with biological samples obtained from infected patients, such as laboratory staff.

- Level 3 (Low exposure group; $n=535$ ): workers who were not in contact with SARS-CoV-2 at all, such as administrative, catering, security, housekeeping, and maintenance staff.

Since there was no information on the working activity of some subject, 27 workers were not included in any group.

A questionnaire was created to collect demographic and clinical data.

\section{COVID-19 Training}

Since the beginning of the pandemic, voluntary trainings have been provided to health care staff. For those who could not attend, online trainings were available.

Health workers had to be prepared to face different challenges. Therefore medical training programs were conducted and implemented on general health areas and also on more specific topics according to the medical specialty, nursery, or health care assistance.

Health educational messages have been disseminated in different ways. First, some educational videos were recorded and posted on the intranet. Posters and educational materials were also displayed throughout the hospital facility. Then, face-to-face recommendations were given for the most appropriate use of Personal Protective Equipment (PPE). In order to protect themselves and prevent transmission in the hospital facility, health care workers were trained on how to put on, remove, and dispose the PPE. 
Workshops were also organized to evaluate many different scenarios. For example, a workshop on hand hygiene by fluorescence analysis to assess hand washing was conducted. Also workshops based on patient medical care with or without exploration or workshops for orderlies on the transport of the patients from one place to another before and after procedures were organized. Each scenario recreates hand hygiene and PPE moments (double gown, impermeable gown, apron, goggles, or a face shield, etc.).

Finally, the implementation of every procedure included in the safety protocol was supervised by a preventive physician and a nurse in order to clarify situations and to correct bad practices.

\section{Real-Time RT-PCR Assay}

Two types of automatic extractors were used to obtain viral RNA from clinical samples: MagCore HF16 (RBC bioscience, Taipei, Taiwan) and Nimbus Microlab Seegene (Hamilton Company, Bonaduz, Switzerland). RNA amplification was made using two real-time PCR platforms: $q$ COVID-19 (Genomica,Madrid, Spain) and Allplex 2019-nCoV assay (Seegene, Seoul, South Korea). The CFX96 ${ }^{\mathrm{TM}}$ (Bio-Rad) Real-Time Detection System was used.

These kits were used according to the manufacturer's instructions for the handling and the interpretation of the results.

\section{The Abbott SARS-CoV-2 IgG Assay (Abbott Laboratories Inc. Illinois, USA)}

The SARS-CoV-2 IgG assay is an automated, two-step immunoassay for the qualitative detection of $\mathrm{IgG}$ antibodies to SARS-CoV-2 in human serum and plasma using chemiluminescent microparticle immunoassay (CMIA) technology (Architect System).

The assay is designed to detect $\operatorname{IgG}$ antibodies against the nucleocapsid protein of SARS-CoV-2. A minimum of $100 \mu \mathrm{l}$ of serum or plasma (EDTA) is required.
Sample, SARS-CoV-2 antigen-coated paramagnetic microparticles, and assay diluent are combined and incubated $\left(36.4-37.6{ }^{\circ} \mathrm{C}\right)$. The IgG antibodies to SARS-CoV-2 present in the sample bind to the SARS-CoV-2 antigencoated microparticles. The mixture is washed. Anti-human IgG acridinium-labeled conjugate is added to create a reaction mixture and incubated $\left(36.4-37.6{ }^{\circ} \mathrm{C}\right)$. Following a wash cycle, Pre-Trigger and Trigger Solutions are added.

The resulting chemiluminescent reaction is measured as a relative light unit (RLU). There is a direct relationship between the amount of IgG antibodies to SARS-CoV-2 in the sample and the RLU detected by the system optics. This relationship is reflected in the calculated Index (S/C). The presence or absence of IgG antibodies to SARS-CoV-2 in the sample is determined by comparing the chemiluminescent RLU in the reaction to the calibrator RLU. The cutoff is 1.4 Index ( $\mathrm{S} / \mathrm{C})(\geq 1.4$ Positive; $<1.4$ Negative).

This assay was performed according to the manufacturer's instructions.

\section{Statistical Analysis}

Statistical analysis was carried out using the statistical package STATA/IC version 13.1 (StataCorp, Texas, USA). Continuous data were expressed as mean and interquartile range (IQR), while categorical data were expressed as frequencies and percentages. Comparison between variables were made using two-tailed Fisher's exact test or $t$ test. For these comparisons, a $P$ value $\leq 0.05$ was considered significant.

\section{Results}

The entire hospital staff $(n=2781)$ was screened included in this study. The median age was 45.52 years $(\mathrm{IQR}=25.26)$ and $60.1 \%(n=1672)$ were women. Approximately $26.3 \%$ $(n=734)$ were military personnel and $72.6 \%$ were civilian $(n=2020)$ (Table 1$)$. Twenty seven subjects were not included in the analysis between the three levels of exposure due to the lack of information on the level of exposition.
Table 1 Results from workers on the basis of the three levels of exposure

\begin{tabular}{lccccc}
\hline & $\begin{array}{l}\text { Level 1 } \\
(\mathrm{No}=1250)\end{array}$ & $\begin{array}{l}\text { Level 2 } \\
(\mathrm{No}=969)\end{array}$ & $\begin{array}{l}\text { Level 3 } \\
(\mathrm{No}=535)\end{array}$ & $\begin{array}{c}\text { Total } \\
(\mathrm{No}=2781)\end{array}$ & $P$ value* \\
\hline IgG positive No (\%) & $244(19.5)$ & $139(14.3)$ & $67(12.5)$ & $450(16.2)$ & $0.0002^{*}$ \\
rRT-PCR positive No (\%) & $12(1.0)$ & $10(1.0)$ & $8(1.5)$ & $30(1.1)$ & 0.6171 \\
Female No (\%) & $865(69.2)$ & $606(62.5)$ & $188(35.1)$ & $1672(60.1)$ & $<0.0001^{*}$ \\
Male No (\%) & $385(30.8)$ & $363(37.5)$ & $347(64.9)$ & $1095(39.8)$ & \\
COVID-19 training No (\%) & $580(74.5)$ & $332(62.2)$ & $147(44.8)$ & $1060(64.5)$ & $<0.0001^{*}$ \\
Military No (\%) & $383(30.6)$ & $166(17.1)$ & $185(34.5)$ & $734(26.3)$ & $<0.0001^{*}$ \\
Civilian No (\%) & $867(69.3)$ & $803(82.8)$ & $350(65.4)$ & $2020(72.6)$ & \\
\hline
\end{tabular}

$*$ A $P$ value $\leq 0.05$ was considered significant 
A total of 2781 health care workers were screened, 30 $(1.1 \%)$ of whom were infected with SARS-CoV-2; there were no statistically significant differences in the proportion of SARS-CoV-2-positive PCR detection between the three level of exposure (Level 1: 1.0\%, level 2: 1.0\%, level 3: $1.5 \% P=0,6171$ ) (Table 1).

SARS-CoV-2-IgG antibodies were detected in 450 employees (16.2\%) out of 2781. Statistically significant differences were observed between the different groups.

Specifically, 244 subjects on level 1 (19.5\%), 139 subjects on level $2(14.3 \%)$, and 67 subjects on level 3 $(12.5 \%)$ were positive for SARS-CoV-2-IgG antibodies $(P=0.0002)$ (Table 1).

263 subjects $(58.4 \%)$ out of 450 with detectable antibodies reported COVID-19-associated symptoms in the past 3 months including fever $(67.1 \%)$, headache $(62.2 \%)$, general malaise $(63.6 \%)$, cough $(67.1 \%)$, anosmia $(49.7 \%)$, ageusia $(40.6 \%)$, and diarrhea $(39.8 \%)$. Moreover, these symptoms were observed in 158 (64.7\%) subjects from level 1 of exposure, 72 (51.8\%) from level 2 , and $33(49.3 \%)$ from level $3(P=0.0007)$.

No differences in the rate of seroprevalence between men and women could be observed $(16.1 \%$ and $15.9 \%$, respectively, $P=0.865)$. However, when considering the level of exposure, the positive detection of $\mathrm{IgG}$ was significantly greater in men in level 3 than in level 1 and 2 $(67.2 \%, 36.5 \%$, and $33.1 \%$, respectively, $P=0.001)$.

1060 subjects $(64.5 \%)$ out of 1642 who answered the questionnaire had received training against COVID-19. The percentage of employees with COVID-19 training was different in each group (Level 1: $74.5 \%$, level 2: $62.2 \%$, level 3: $44.8 \% P=0.0001$ ) (Table 1). SARSCoV-2-IgG antibodies were detected in 154 employees $(14.5 \%)$ out of 1060 who received training against SARSCoV-2 and 108 employees (18.6\%) out of 582 who did not receive any training $(P=0.035)$. The seroprevalence was higher in those subjects without COVID-19 training at every level of exposure. Statistically significant differences were observed in level 1 of exposure, with $16.7 \%$ of positive subjects to IgG receiving COVID-19 training as compared to $25.3 \%$ positive subjects not receiving it $(P=0.009)$.

Overall, military personnel seropositivity was lower than civilian personnel $(15.1 \%, 16.7 \%$, respectively, $P=0.2975$ ). When comparing the positive rates of $\operatorname{IgG}$ in military and civilian personnel depending on the level of exposure, no differences were observed for level 1 (18.2\% and $20.0 \%$, respectively; $P=0.4616$ ), more civilian were positive in level $2(16.0 \%$ vs. $6 \% ; P=0.0008)$, and more military personnel were positive in level $3(16.7 \%$ vs. $10.2 \% ; P=0.0315)$.

\section{Discussion}

The seroprevalence and SARS-CoV-2 infection in health care workers from a military hospital was determined in the present study. The main results showed that the prevalence of positive infection was low (1.1\%) and that $16.2 \%$ of the sample showed positive IgG against SARS-CoV-2.

This hospital is located in Madrid, one of the regions with the highest COVID-19 rates in the country [17], which could explain the high rate of antibodies detection. However, no differences were observed between the results from the present study and the expected seroprevalence of $15 \%$ based on an estimate from modeling studies for the overall Spanish population in March 2020 [18].

Similar studies performed in other countries have observed higher infection rates in health care workers. In a study of 1533 employees from the UK, 282 (18\%) tested positive for SARS-CoV-2 infection [19].

The seroprevalence was higher in the high exposure group (level 1) as compared to the moderate (level 2) and low exposure group (level 3). These differences could be in part explained by the type of activity carried out, since Level 1 employees have daily contact with COVID-19 patients.

Another finding from the present study is that an important approach to prevent infection between patient and staff is to receive training on COVID-19 protocols, as for example hygiene guidelines. It needs to be remarked that the overall rate of employees with COVID-19 training was $64.5 \%$. This cohort of patients presented significantly less seroprevalence of antibodies against SARS-CoV-2 as compared to employees without any COVID-19 training $(14.5 \%$ vs $18.6 \%)$. Moreover, these findings could be observed at every level of exposure.

A total of 263 seropositive employees (58\%) had previously been diagnosed with COVID-19, whereas $42 \%$ were asymptomatic, which denotes that early detection/ screening programs should be implemented in health care workers to decrease in-hospital transmission and to maximize the available workforce [19]. This is in accordance with other studies observing similar rates of asymptomatic subjects [20].

Military and civilian personnel showed slightly different results for the prevalence of $\operatorname{IgG}(15.1 \%$ and $16.7 \%$, respectively). When analyzing the seroprevalence by the risk of exposure to SARS-CoV-2, civilian subjects within level 1 and 2 presented higher positive results for IgG than the military group. This could be explained by the fact that military personnel are trained throughout their professional life to attend emergency situations. Also they received nuclear, radiologic, biologic, and chemical courses on regular basis, allowing military personnel to 
enhance their preparedness to any arising health emergency situation. Positive cases associated to level 3 subjects were mainly related to external transmission due to close contacts with positive relatives during family gatherings or others.

An important limitation related to the study design should be acknowledged, since descriptive observational approaches do not necessarily imply causality relationships. Moreover, this study design can sometimes be useless and can also lead to confounding factors when dealing with short-term or infrequent illnesses. Also, it should be taken into consideration that the number of participants still remains limited even if the entire health care staff had been included in the study, which can be explained by the reduced size of the hospital.

Finally, the accurate sensitivity and specificity of the immunological assay performed still remain unknown as no "gold standard" test is currently available for the determination of antibodies against SARS-CoV2 infection. Additionally, the Abbott SARS-CoV-2 IgG test is also limited as it only detects $\operatorname{IgG}$ antibodies against the nucleocapsid.

As a strong point, to the best of our knowledge, this is one of the first studies on anti-SARS-CoV-2 IgG antibodies comparing military to civilian health care workers. However, further multicenter studies with a large number of subjects from different military hospitals would be necessary to further evaluate the seropositivity in these different cohorts.

\section{Conclusion}

Taking into consideration the limitation found in the present study, we can conclude that the global seroprevalence data of the hospital was as expected. Three factors were associated to the prevalence of patients positive to SARS-CoV-2 IgG antibodies. First, health workers who attended COVID-19 trainings had a lower seroprevalence rate than those who did not attend them, suggesting the great importance of trainings in safety protocols. Second, a lower seroprevalence rate among military employees as compared to the civilian personnel could be observed. And third, subjects with higher risk of exposure to SARS-CoV2 had higher seroprevalence and higher infected rates.

Acknowledgements The authors would like to thank The Zendal Group and Occupational Health and Safety Service at Hospital Central de la Defensa Gómez Ulla who have contributed in different ways to make this study happen. The Zendal Group is made up by Ma Isabel Lopez Figueras, Isabel Ortiz Mendoza, Ma Gracia García Gonzalez, Encarnacion Mérida Arias, Jose Luis Martin Prieto, Francisca DoctorRomero Del Hombre Bueno, Carmen Luisa Suarez Blanco, Cecilia Garcia-Roca Lopez and Ma Vicenta García Rosado.

Author Contributions Study concept and design: MSS, ACB and MZC. Clinical and microbiological data acquisition: MSS, ASP, EMM,
CAF, CYV. Sample processing; MSS, MZC. Statistical analysis and interpretation of data: ACB. Writing of the manuscript: MSS, ACB, MZC. Critical revision of the manuscript: MMM. All authors read and approved the final manuscript.

Funding This research received no specific grant from any funding agency in the public, commercial, or not-for-profit sectors.

Data Availability Not applicable.

Code Availability Not applicable.

\section{Declarations}

Conflict of interest The authors report no conflict of interest related to this study.

Ethical Approval The study was conducted according to the ethical requirements established by the Declaration of Helsinki. The Ethics Committee of Hospital Central de la Defensa Gómez Ulla (Madrid) $(58 / 20)$ approved the study.

Consent to Participate Informed consent was obtained from every participant enrolled in the study.

Consent for Publication Patients gave a written consent to approve publishing their data.

\section{References}

1. Guan WJ, Ni ZY, Hu Y, Liang WH, Ou CQ, He JX, Liu L, Shan H, Lei CL, Hui DSC et al (2020) Clinical characteristics of coronavirus disease 2019 in China. N Engl J Med 382(18):1708-1720. https://doi.org/10.1056/NEJMoa2002032

2. Hick JL, Biddinger PD (2020) Novel coronavirus and old lessons-preparing the health system for the pandemic. N Engl J Med 382(20):e55. https://doi.org/10.1056/NEJMp2005118

3. Actualizacion COVID-19 España.pdf. https://doi.org/10.1056/ NEJMp2005118

4. Chen N, Zhou M, Dong X, Qu J, Gong F, Han Y, Qiu Y, Wang J, Liu Y, Wei Y et al (2020) Epidemiological and clinical characteristics of 99 cases of 2019 novel coronavirus pneumonia in Wuhan, China: a descriptive study. Lancet 395(10223):507-513. https:// doi.org/10.1016/S0140-6736(20)30211-7

5. Luo Y, Trevathan E, Qian Z, Li Y, Li J, Xiao W, Tu N, Zeng Z, Mo P, Xiong Y et al (2020) Asymptomatic SARS-CoV-2 infection in household contacts of a healthcare provider, Wuhan, China. Emerg Infect Dis 26(8):1930-1933. https://doi.org/10.3201/eid26 08.201016

6. seimc-rc-2020-Posicionamiento_SEIMC_diagnostico_microbiologico_COVID19.pdf

7. Li Z, Yi Y, Luo X, Xiong N, Liu Y, Li S, Sun R, Wang Y, Hu B, Chen W et al (2020) Development and clinical application of a rapid IgM-IgG combined antibody test for SARS-CoV-2 infection diagnosis. J Med Virol. https://doi.org/10.1002/jmv.25727

8. Corman VM, Landt O, Kaiser M, Molenkamp R, Meijer A, Chu DK, Bleicker T, Brunink S, Schneider J, Schmidt ML et al (2020) Detection of 2019 novel coronavirus (2019-nCoV) by real-time RT-PCR. Euro Surveill 25(3):2000045. https://doi.org/10.2807/ 1560-7917

9. Zhang W, Du RH, Li B, Zheng XS, Yang XL, Hu B, Wang YY, Xiao GF, Yan B, Shi ZL et al (2020) Molecular and serological 
investigation of 2019-nCoV infected patients: implication of multiple shedding routes. Emerg Microbes Infect 9(1):386-389. https://doi.org/10.1080/22221751.2020.1729071

10. Pan Y, Li X, Yang G, Fan J, Tang Y, Zhao J, Long X, Guo S, Zhao Z, Liu Y et al (2020) Serological immunochromatographic approach in diagnosis with SARS-CoV-2 infected COVID-19 patients. J Infect. https://doi.org/10.1016/j.jinf.2020.03.051

11. Guo L, Ren L, Yang S, Xiao M, Chang D, Yang F, Dela Cruz CS, Wang Y, Wu C, Xiao Y et al (2020) Profiling early humoral response to diagnose novel coronavirus disease (COVID-19). Clin Infect Dis 71(15):778-785. https://doi.org/10.1093/cid/ciaa310

12. Black JRM, Bailey C, Przewrocka J, Dijkstra KK, Swanton C (2020) COVID-19: the case for health-care worker screening to prevent hospital transmission. Lancet 395(10234):1418-1420. https://doi.org/10.1016/S0140-6736(20)30917-X

13. Rostami A, Sepidarkish M, Leeflang MMG, Riahi SM, Nourollahpour Shiadeh M, Esfandyari S, Mokdad AH, Hotez PJ, Gasser RB (2021) SARS-CoV-2 seroprevalence worldwide: a systematic review and meta-analysis. Clin Microbiol Infect 27(3):331-340. https://doi.org/10.1016/j.cmi.2020.10.020

14. Wu F, Wang A, Liu M et al Neutralizing antibody responses to SARS-CoV-2 in a COVID-19 recovered patient cohort and their implications.pdf

15. Wolfel R, Corman VM, Guggemos W, Seilmaier M, Zange S, Muller MA, Niemeyer D, Jones TC, Vollmar P, Rothe C et al (2020) Virological assessment of hospitalized patients with COVID-2019. Nature 581(7809):465-469. https://doi.org/10. 1038/s41586-020-2196-x

16. Zhao J, Yuan Q, Wang H, Liu W, Liao X, Su Y, Wang X, Yuan J, Li T, Li J et al (2020) Antibody responses to SARS-CoV-2 in patients of novel coronavirus disease 2019. Clin Infect Dis. https:// doi.org/10.1093/cid/ciaa344
17. Pollan M, Perez-Gomez B, Pastor-Barriuso R, Oteo J, Hernan MA, Perez-Olmeda M, Sanmartin JL, Fernandez-Garcia A, Cruz I, Fernandez de Larrea N et al (2020) Prevalence of SARS-CoV-2 in Spain (ENE-COVID): a nationwide, population-based seroepidemiological study. Lancet 396(10250):535-544. https://doi.org/ 10.1016/S0140-6736(20)31483-5

18. Report13 Estimating the number of infections and the impact of nonpharmaceutical interventions on COVID-19 in 11 European countries.pdf

19. Keeley AJ, Evans C, Colton H, Ankcorn M, Cope A, State A, Bennett T, Giri P, de Silva TI, Raza M (2020) Roll-out of SARSCoV-2 testing for healthcare workers at a large NHS Foundation Trust in the United Kingdom, March 2020. Euro Surveill 25(14):2000433. https://doi.org/10.2807/1560-7917.ES.2020.25. 14.2000433

20. Garcia-Basteiro AL, Moncunill G, Tortajada M, Vidal M, Guinovart C, Jimenez A, Santano R, Sanz S, Mendez S, Llupia A, Aguilar R, Alonso S, Barrios D, Carolis C, Cistero P, Choliz E, Cruz A, Fochs S, Jairoce C, Hecht J, Lamoglia M, Martinez MJ, Mitchell RA, Ortega N, Pey N, Puyol L, Ribes M, Rosell N, Sotomayor P, Torres S, Williams S, Barroso S, Vilella A, Munoz J, Trilla A, Varela P, Mayor A, Dobano C (2020) Seroprevalence of antibodies against SARS-CoV-2 among health care workers in a large Spanish reference hospital. Nat Commun 11:3500. https:// doi.org/10.1038/s41467-020-17318-x

Publisher's Note Springer Nature remains neutral with regard to jurisdictional claims in published maps and institutional affiliations. 